\title{
Estratégias desenvolvidas por usuários de crack para lidar com os riscos decorrentes do consumo da droga
}

Strategies developed by crack users to deal with the risks resulting from the consumption

Luciana Abeid Ribeiro', Zila M. Sanchez', Solange Aparecida Nappo²

\section{RESUMO}

Objetivos: $O$ objetivo deste estudo foi identificar, sob a ótica de usuários de crack, quais são as estratégias que eles utilizam para minimizar ou evitar os riscos decorrentes do consumo de crack. Método: Utilizou-se método qualitativo de pesquisa, desenvolvido mediante entrevistas semiestruturadas em profundidade. Foi entrevistada uma amostra intencional por critérios, composta por 30 usuários de crack, selecionados por meio de informantes-chave e distribuídos em oito diferentes cadeias. As entrevistas foram transcritas literalmente, inseridas e analisadas no software NVivo 8, com exploração dos dados mediante a técnica de análise de conteúdo. Resultados: Os entrevistados acreditam que os maiores riscos decorrentes da dependência do crack sejam os relacionados aos efeitos psíquicos da droga, como fissura, sintomas paranoides transitórios e sintomas depressivos, assim como os decorrentes da ilegalidade dela, como a polícia e as questões referentes ao tráfico. Entretanto, os riscos de complicações físicas do consumo quase não foram apontados. As estratégias se concentraram no controle dos efeitos psíquicos, principalmente pelo consumo de álcool e maconha. Para lidar com as consequências da ilegalidade da droga, mostraram se preocupar com a postura que adotam perante o traficante e a polícia. Conclusões: As estratégias desenvolvidas pelos usuários focam na tentativa de se autoprotegerem principalmente dos episódios de violência e no alívio de sintomas desagradáveis causados pela droga - principalmente fissura e sintomas paranoides transitórios. Essas estratégias podem parecer efetivas a curto prazo, porém apresentaram riscos de longo prazo, tais como dependência de álcool e maconha.

\section{ABSTRACT}

Objectives: The aim of this study was to identify, from the perspective of crack users, what are the strategies used to minimize or avoid the risks associated with consumption of crack. Method: A qualitative research method was used, developed through semi-structured in depth interviews. It was interviewed a criterion sample composed of 30 crack users, selected through key informants and distributed in eight different chains. The interviews were verbatim transcribed, entered and analyzed in NVivo 8 software. Data was analyzed by "content analysis" technique. Results: Respondents believe that the greatest risks of dependence on crack cocaine are related to the psychic effects of the drug like craving, transient paranoid symptoms and depressive symptoms - and those

1 Universidade Federal de São Paulo (Unifesp), Departamento de Psicobiologia, Centro Brasileiro de Informações sobre Drogas Psicotrópicas (CEBRID). 2 Unifesp, Departamento de Psicobiologia.

Endereço para correspondência: Luciana Abeid Ribeiro Rua Botucatu, 862, Edifício Ciências Biomédicas, $1^{\circ}$ andar 04023-062 - São Paulo, SP, Brasil

E-mail: luciana.abeid@unifesp.br 


\section{Keywords}

Crack-cocaine, risks, behaviors, qualitative method, Sao Paulo/Brazil. stemming from the illegality of it, such as the police and issues relating to trafficking. However, the risk of physical complications of consumption has hardly been mentioned. The strategies focused on control of the psychic effects, mainly by consumption of alcohol and marijuana. To deal with the consequences of the unlawful drug they showed concern about how to relate to the dealers and police officers. Conclusions: The strategies developed by crack users are focused on trying to protect their selves against violence and to relief from unpleasant psychic effects - mainly craving and transient paranoid symptoms. These strategies may seem effective in the short term. However, showed long-term risks, such as alcohol and marijuana dependence.

\section{INTRODUÇÃO}

O crack é um potente estimulante do sistema nervoso central com alto potencial de dependência'. Apesar de não figurar nos dados estatísticos brasileiros entre as drogas ilícitas mais consumidas $\left(0,7 \%\right.$ da população fez uso na vida) ${ }^{2}$, merece atenção por causa dos riscos associados ao padrão de uso compulsivo. É frequente o envolvimento em atividades violentas e ilícitas como roubos, assaltos e tráfico ${ }^{3,4}$ e atividades sexuais de risco para obtenção de dinheiro ou droga ${ }^{5-7}$, causando problemas sociais e de saúde pública.

Ademais, o estilo de vida adotado pelos usuários, geralmente desregrado e permeado por atividades ilícitas, torna-os especialmente vulneráveis a mortes por causas externas ${ }^{6}$. Ribeiro et al. ${ }^{8}$,em estudo de follow-up de cinco anos com usuários de crack, mostraram que $18 \%$ da amostra faleceram no período. Essa taxa é sete vezes maior que a mortalidade geral na cidade de São Paulo no mesmo período. Esses autores, ainda, observaram que $56,6 \%$ das mortes foram homicídios ${ }^{8}$.

Há evidências de que alguns usuários conseguem, de alguma forma, manter-se vivos e ativos no consumo de crack por muitos anos, apesar da série de adversidades e riscos. Como exemplo, em continuação por mais sete anos de seguimento do mesmo follow-up apresentado anteriormente (Ribeiro et al.) ${ }^{8}$, foi visto que as mortes declinaram consideravelmente - apenas duas mortes no período ${ }^{9}$. Dessa forma, vê-se uma estabilização nas mortes com o passar do tempo, o que sugere o aprendizado de estratégias de proteção.

Falck et al. ${ }^{10}$, em seguimento de nove anos a usuários de crack, também observaram alguma adaptação à cultura do crack, permitindo, assim, que a maioria da amostra (64\%) mantivesse o uso de crack inalterado por quase uma década, sem períodos de abstinência superiores a seis meses.

Entretanto, ainda existe uma deficiência no que tange à compreensão das práticas e dinâmicas sociais relacionadas ao crack $^{11}$, especialmente entre usuários de longo tempo ${ }^{10}$. Dessa forma, há necessidade de exploração e descrição em profundidade das estratégias que parecem regular e permitir o uso do crack por longo tempo ${ }^{4}$. Assim, o objetivo deste estudo é o de identificar, sob a ótica dos usuários, os riscos aos quais estão sujeitos e, a partir do conhecimento desses riscos, explorar as estratégias empregadas para minimizá-los.

\section{METODOLOGIA}

Utilizou-se metodologia qualitativa de pesquisa, uma vez que essa abordagem procura descrever e analisar culturas e comportamentos humanos a partir do ponto de vista dos investigados ${ }^{12}$. Tal método permite identificar valores, crenças, opiniões e comportamentos, por meio dos seus próprios conceitos, revelados de forma aberta em seus discursos ${ }^{13,14}$.

\section{Amostra}

A obtenção da amostra originou-se a partir de entrevistas com oito informantes-chave - pessoas com conhecimento especial tanto do tópico de interesse da pesquisa quanto da população em estudo ${ }^{12}$. Esses intermediários funcionaram como facilitadores do contato entre investigadores e sujeitos da amostra.

A amostra selecionada foi intencional por critérios ${ }^{14}$. Foram selecionados casos ricos em informação para entrevistas em profundidade e nas informações específicas para objeto de estudo, ou seja, vivência na dependência de $\mathrm{crack}^{12}$.

Como critério de inclusão na amostra, definiu-se o usuário de crack como aquele que fez uso da droga por no mínimo um ano. Esse tempo foi definido como suficiente para abranger casos ricos em informação da cultura do crack, ou seja, informação suficiente para caracterizar a atual situação de uso da droga ${ }^{3}$. Determinou-se esse tempo ao se considerar a baixa expectativa de vida do usuário evidenciada nas primeiras gerações estudadas no Brasili, ${ }^{315}$. Os entrevistados foram selecionados na cidade de São Paulo, durante os anos de 2008 e 2009.

Os primeiros entrevistados, contatados principalmente pelos informantes-chave ${ }^{12,16}$, sucessivamente indicavam outros, por meio da técnica de "bola de neve"17. Desse processo, foram originadas oito cadeias com no máximo cinco entrevistados cada. Tal procedimento visou à abrangência do maior número possível de perfis de usuários. Os temas foram explorados até seu esgotamento (ponto de saturação teórica), ou seja, quando as informações passaram a se repetir e nenhum dado novo possibilitou compreensões adicionais sobre o fenômeno em estudo ${ }^{14}$. Esse fato foi constatado quando novos entrevistados chegaram à redundância, por escassez de novas informações e repetição dos discursos ${ }^{12}$. 
O ponto de redundância (ou saturação teórica) estabeleceu o encerramento da coleta em 30 entrevistas.

\section{Instrumentos utilizados}

Foram realizadas entrevistas em profundidade, baseadas em roteiro semiestruturado. O roteiro foi elaborado a partir do subsídio das entrevistas com os informantes-chave ${ }^{14}$, configurando-se em um roteiro misto, ou seja, formado por algumas questões previamente padronizadas e outras elaboradas no decorrer da entrevista. As questões padronizadas têm por finalidade permitir a comparabilidade de respostas, reduzir a interferência do entrevistador na investigação e facilitar a organização e análise dos dados. As outras questões surgiam para esclarecer tópicos particulares nascidos em cada entrevista, permitindo aprofundamento, de modo a aumentar a compreensão da problemática da investigação ${ }^{12,16}$.

O roteiro abordava dados sociodemográficos, histórico do consumo de drogas, riscos decorrentes do uso do crack e estratégias desenvolvidas para lidar com os riscos. No presente trabalho, a definição de "risco" foi entendida segundo a interpretação do próprio usuário, ou seja, aquilo que ele entende e define como risco.

As questões referentes aos dados socioeconômicos foram avaliadas por meio da escala de Critério de Classificação Econômica Brasil, elaborada pela ABEP (Associação Brasileira de Empresas e Pesquisa) ${ }^{18}$.

O áudio das entrevistas foi gravado, conforme prediz a técnica qualitativa ${ }^{16}$. As entrevistas tiveram duração média de 90 minutos.

\section{Análise dos dados}

Cada entrevista foi identificada por um código alfanumérico: primeira letra do nome do entrevistado e idade. O áudio foi totalmente transcrito, possibilitando desenvolver técnicas de análise de conteúdo com referencial teórico baseado nas definições de Bardin ${ }^{19}$. Nessa etapa, optou-se pelo auxílio do programa computadorizado NVivo versão $8^{20}$. Esse programa permitiu maior consistência na análise dos dados qualitativos, uma vez que facilitou o armazenamento do material transcrito, organização e codificação das entrevistas ${ }^{14}$.

Este trabalho foi aprovado pelo Comitê de Ética da Universidade Federal de São Paulo/Hospital São Paulo.

\section{RESULTADOS}

\section{Caracterização da amostra}

Foram entrevistados 30 usuários de crack. A amostra foi majoritariamente composta por homens ( $n=20)$, com idade média de 32 anos (variando entre 20 e 47) e tempo médio de uso de crack de 11,5 anos (variando de 1 a 20 anos de uso). A maioria da amostra estava desempregada ou realizava algum tipo de trabalho informal. Houve concentração dos entrevistados na classe socioeconômica E (de acordo com os parâmetros do Critério de Classificação Econômica Brasil), porém com parte da amostra variando entre as classes D e A2. A escolaridade variou de ensino fundamental incompleto a superior completo, porém com concentração nos níveis de escolaridade mais baixos. O estado civil predominante foi separado. A composição da amostra pode ser observada na tabela 1.

\section{Riscos decorrentes do uso do crack}

Os riscos sugeridos pelos entrevistados foram classificados em três grandes categorias: 1) riscos decorrentes dos efeitos psíquicos da droga, 2) riscos de complicações físicas decorrentes do uso da droga, 3) riscos decorrentes da ilegalidade da droga.

Tabela 1. Composição da amostra

\begin{tabular}{|c|c|}
\hline Descrição da amostra & N \\
\hline \multicolumn{2}{|l|}{ Sexo } \\
\hline Masculino & 20 \\
\hline Feminino & 10 \\
\hline \multicolumn{2}{|l|}{ Faixa etária } \\
\hline $20-29$ & 12 \\
\hline $30-39$ & 13 \\
\hline $40-47$ & 5 \\
\hline \multicolumn{2}{|l|}{ Tempo médio de uso de crack } \\
\hline $1-3$ & 2 \\
\hline $4-9$ & 7 \\
\hline $10-15$ & 13 \\
\hline $16-20$ & 8 \\
\hline \multicolumn{2}{|l|}{ Trabalho } \\
\hline Desempregado & 13 \\
\hline Trabalho informal & 12 \\
\hline Trabalho formal & 5 \\
\hline \multicolumn{2}{|l|}{ Classe econômica* } \\
\hline A ou $B$ & 2 \\
\hline Cou D & 11 \\
\hline $\mathrm{E}$ & 17 \\
\hline \multicolumn{2}{|l|}{ Escolaridade } \\
\hline Fundamental incompleto & 9 \\
\hline Fundamental completo & 6 \\
\hline Médio incompleto & 4 \\
\hline Médio completo & 7 \\
\hline Superior incompleto & 3 \\
\hline Superior completo & 1 \\
\hline \multicolumn{2}{|l|}{ Estado civil } \\
\hline Solteiro & 9 \\
\hline Casado & 4 \\
\hline Separado & 17 \\
\hline
\end{tabular}




\section{1) Riscos decorrentes dos efeitos psíquicos da droga}

Os riscos decorrentes dos efeitos psíquicos da droga estão associados especialmente aos quadros de fissura e paranoia. Em decorrência desses, os riscos mais associados são: lesões físicas devidas a brigas, comportamento sexual arriscado, detenção policial e perda de vínculos.

\section{Lesões físicas}

Apresentam como risco o aumento de agressividade e lesões consequentes. O usuário, durante o uso, torna-se agressivo pelo medo de ser roubado e de se ver sem a droga. Quando o suprimento da droga começa a escassear, os desentendimentos intensificam-se, a discussão foca-se em alguém ter usado mais ou em quem irá conseguir mais dinheiro e droga. Julgam a fissura como responsável pelo aumento da agressividade, com contribuição dos sintomas paranoides. Estes últimos, caracterizados principalmente por ideias e delírios persecutórios, eventualmente culminam em brigas por juízo prejudicado da realidade:

"Você pode usar droga e ficar encanada igual a mim. Você acha que tem alguém vindo, é uma coisa de louco. E tem dia que aquela pessoa que você usou o mês inteiro com ela, nunca fez nada, aquele dia ela pensa que você quer matar ela e o que tiver que puder te acertar, ela acerta em você." (A25F)

\section{Comportamento sexual arriscado: gravidez indesejada e doenças sexualmente transmissíveis}

Um segundo bloco de riscos decorrentes da fissura aparece na busca por recursos para a compra do crack. A modalidade de obtenção de recurso mais citada entre as mulheres foi a prostituição, também observada em alguns homens da amostra. Os riscos dessa prática concentraram-se em gestação indesejada e a consequente tentativa de aborto, além de contaminação por doenças sexualmente transmissíveis, conforme segue exemplo:

"Traz (problemas). Traz porque o pai do meu filho foi assim, eu transei com ele só por causa do crack." (A21F)

O uso inconsistente de preservativos foi corrente; a urgência pela droga sobrepõe-se aos cuidados que acreditavam necessários.

\section{2) Riscos de complicações físicas decorrentes do uso da droga}

A segunda classe de riscos identificada nas entrevistas está associada a riscos de complicações físicas decorrentes do uso do crack, como overdose, emagrecimento e insônia.

\section{Overdose}

A minoria da amostra relatou já ter vivenciado overdose. Episódios definidos pelos usuários como overdose foram aqueles relacionados com algum tipo de atendimento hospitalar, ou seja, efeitos percebidos como extremamente graves. Segue um exemplo desses episódios:
"Umas três vezes (três episódios de overdose). Assim, comecei a sentir falta de ar na rua e a língua começou a enrolar, e na hora que eu cheguei dentro da ambulância eu comecei a me bater." (E2OF)

Quanto ao risco da overdose seguido de morte, poucos relataram já terem visto ou ouvido falar. Alguns deixaram claro que têm medo dessa complicação, outros sequer acreditam nessa possibilidade.

\section{Emagrecimento e insônia}

O problema orgânico mais relatado foi falta de apetite e emagrecimento intenso. Os fatores que contribuem para o emagrecimento são: supressão do apetite, inquietação psicomotora e longas caminhadas em busca por crack nos momentos de fissura.

"Tipo, eu não como, né? E eu ando muito. Então por isso que eu perco de dois a três quilos (em uma semana)." (M34M)

Os entrevistados evidenciaram, ainda, ter extrema dificuldade para dormir, emendando o dia com a noite por longos períodos. A insônia ocorre por duas vias simultâneas: pelo efeito excitatório da droga e pelo desejo de usar mais, que repercute na busca contínua da droga. Cabe destacar que tanto o emagrecimento intenso quanto a insônia, apesar de repercutirem como complicações físicas decorrentes do uso do crack, estão intimamente ligados aos efeitos psíquicos justificados pelo farmacologia excitatória da droga.

\section{3) Riscos decorrentes da ilegalidade da droga}

A terceira classe de riscos identificada decorre da ilegalidade da droga e da vivência do tráfico. Esses riscos estão associados principalmente à violência na bocada*, originada tanto do grupo de traficantes quanto da polícia.

\section{Violência nas "bocadas"}

A violência na bocada foi apontada como um dos principais riscos do uso do crack e se intensifica quando as regras locais do tráfico são descumpridas. O principal risco seria não honrar dívidas com o traficante, pois uma das consequências pode ser a morte do usuário.

"É, aí mataram ele porque ele estava devendo umas parada de crack pros cara. Então mataram ele (irmão do entrevistado)." (R25M)

Roubar nos arredores da bocada e usar a droga nesse ambiente também foram apontados como fontes de confusões com o traficante. Esses comportamentos podem chamar atenção da polícia, o que prejudica a dinâmica local. Assim, roubar ou usar o crack no ambiente de compra também resulta em punições, sobretudo, em agressões físicas.

\footnotetext{
*Local de venda de droga
} 


\section{Polícia}

As questões relacionadas à polícia apresentadas nos discursos revelam estreita interface com o tráfico, seja por medo de serem abordados pela polícia ou obrigados a delatar o local onde foi feita a compra da droga:

"É perigoso assim entre aspas. Porque tem o perigo da polícia te abordar no meio do caminho e te dar uma geral e se você não puder jogar fora ou engolir (a droga). Você não pode falar de quem você comprou." (R32F)

Episódios de violência foram relatados como decorrentes do conflito entre usuários e policiais, intensificados quando o usuário tenta negar o uso do crack.

\section{Estratégias desenvolvidas pelos usuários}

Observou-se que uma mesma estratégia pode destinar-se a diversos riscos e outra ser dirigida a um risco específico. Foram identificadas nove diferentes estratégias, conforme descritas a seguir.

\section{1) Uso em grupo $X$ uso sozinho}

Ter companhia para o uso foi relatada como forma de sanar os medos decorrentes das perturbações auditivas/visuais ou de obter ajuda nos possíveis episódios de overdose.

"No meu caso eu não gostava de usar sozinha por causa das vozes. Eu já achava que eu ia ver o diabo, essas coisas. Eu morria de medo, até hoje." (A25F)

O medo de serem abordados pela polícia e não terem com quem dividir o problema também pesa na decisão de compartilhar o uso.

Já outros relatam que uma estratégia para lidar com o possível risco de lesões, decorrentes dos desentendimentos entre os membros do grupo provocados pela fissura e paranoia, seria utilizar a droga sozinho, sem companhia.

Tal estratégia associa-se ao medo da violência em geral, normalmente briga nos grupos pelo aumento de agressividade, como expresso no seguinte trecho:

"Sozinho, porque outras pessoas podem estar muito loucas, na hora (durante o uso) estar com uma faca na mão, alguma coisa e enfiar na gente." (R25M)

Sozinhos evitariam estímulos para roubarem e riscos consequentes.

\section{2) Utilizar a droga em lugares protegidos}

Locais protegidos para consumo foram percebidos como estratégias para diminuir riscos de violência e lesões. Utilizar crack em casa, seja própria ou de colegas, foi a opção mais comum. Hotéis, especialmente da região central da cidade de São Paulo, zona conhecida como crackolândia, também são habituais. A proximidade com as bocas de venda, a prostituição enraizada nessa região e a "aceitação" dos envolvidos (como os responsáveis pelos hotéis) parecem facilitar o uso. "Já entrei no hotel, aí já tinha uma menina com um ca- chimbo, eu já tinha feito um programa com ela, né? [...] Ali éum hotel próprio pra viciado, 5 reais por meia hora. Tem hotel que é 7 reais uma hora." (M34M)

\section{3) Associar maconha}

A associação de substâncias psicoativas como estratégia para lidar com efeitos do crack fez-se nitidamente representada tanto na quantidade de relatos quanto na variedade de riscos que tenta suprir. Associar maconha ao crack surgiu como principal estratégia de redução da fissura, seja pelo uso de mesclado (cigarro de maconha e crack), seja pelo uso de maconha após o crack (mais frequente na amostra). O uso de mesclado ocorreu para substituir o uso do crack puro. Os usuários descrevem que a pedra gera padrão compulsivo e fissura mais intensos do que o mesclado. O trecho seguinte exemplifica:

"Segura, segura (a fissura). Vocêpega uma pedra e enrola no mesclado, você fuma em três vezes (demora mais tempo para fumar). A pedra não, você fuma rapidinho, é questão de minuto ejá quer outra." (J31M)

O uso de maconha também foi relatado como forma de inibir efeitos estimulantes do crack, principalmente a insônia e a falta de apetite.

Foi visto, porém, que o uso da maconha geralmente continua na abstinência do crack, tornando-se, para alguns entrevistados, uma dependência associada.

\section{4) Associar álcool}

Essa foi a estratégia mais utilizada para aliviar sintomas paranoides transitórios, sobretudo para amenizar o medo e a agressividade:

"Crack e bebida, muita bebida para poder amenizar um pouco a paranoia que é muito forte... então eu pensava, já equilibrava tudo na minha mente: Se eu pegasse três pedras de crack, eu teria que ter uma bebida suficiente para aquilo." (P34M)

O uso do álcool como estratégia para amenizar a fissura foi relatado por muitos entrevistados. Lançou-se mão dessa tática visando cessar a vontade constante do uso do crack. Explicam que, pelo poder "calmante" do álcool, se reduz a energia para busca de dinheiro ou droga, sendo assim um possível controle para a fissura:

"Quando via que a droga tava acabando e a grana também já tinha acabado, ai é quando dá o desespero. Só te resta uma alternativa: pegar uma garrafa de qualquer bebida destilada que você tiver e tomar. Nesta hora você não pode ser racional, você tem que tomar um anestésico, uma coisa que faça você arriar." (J47M)

Assim, o uso do álcool apareceu em toda a extensão do uso do crack, especialmente de modo simultâneo.

Entretanto, alguns discursos apontam para aumento da fissura a partir do uso do álcool. Relatam que o álcool "chama o crack" pela intensificação imediata da fissura. 


\section{5) Controle da quantidade de crack utilizada}

As estratégias que diminuem o risco da overdose (além do uso do álcool) concentraram-se em controlar a quantidade inalada, reduzindo a quantidade da droga colocada no cachimbo. Apontam que há uma medida certa para obtenção do efeito hedônico e proteção quanto à overdose.

"Não, nunca tive overdose... eu usava, colocava aquela medida controlada no cachimbo (...). Porque... Pô, pra dar um barato não precisa ser muita coisa." (M33M)

\section{6) Cuidados para a compra da droga}

Alguns entrevistados relataram preferir comprar a droga em pontos conhecidos para assim evitarem possíveis confusões com traficantes nos primeiros encontros; já outros preferem variar os pontos de compra para garantir o anonimato do uso. Para a escolha de quando comprar a droga, alguns entrevistados dizem contar com ajuda de informantes (pessoas que conhecem a dinâmica do tráfico ou traficantes) para saber qual horário é mais conveniente. Assim, parecem evitar consideravelmente confrontos com policiais.

"Você sempre tem os seus informantes, dependendo do bairro, você sabe por onde a polícia passa, qual o horário que ela passa. Você sempre sabe, sempre na própria boca, né? Porque o traficante ele não pode ser pego." (A25F)

Existe ainda uma forma de compra conhecida como delivery. Essa modalidade de compra acontece quando os usuários têm dinheiro suficiente para pagar pelo serviço de entrega da droga.

"Simplesmente eu to saindo do meu trabalho e vou tomar uma cerveja em algum lugar e falo: 'Aí, meu, me entrega em tal lugar.' Eu tenho a comodidade de ter dinheiro e pagar pro cara vir trazer. Por que eu vou correr risco de ser preso?" (H36M)

\section{7) Cumprir regras do tráfico}

A maioria dos relatos revelou que as regras do tráfico devem ser seguidas rigorosamente, pois as consequências são graves: não fazer dívida foi a mais citada, seguida por não tentar negociar com o traficante, falar pouco no momento da compra e nunca chegar alterado na bocada. Segue um relato que exemplifica a preocupação de um usuário quanto a necessidade de as regras do tráfico serem cumpridas, principalmente não fazer dívidas:

"Ó, cara, daqui a pouco eu te trago (o dinheiro). Aí o cara não traz e, para ele não ir comprar nesse lugar que ele estava devendo, ele ia comprar em outro. Aí, por azar dele, o cara foi e falou: 'Oh, o cara tá gastando lá.' Daí os caras foram e passaram o cerol no mesmo dia (mataram). Dívida, não. É muito perigoso... se o cara não tiver condições de pagar depois, ele tá caçando a morte dele." (A32M)

\section{8) Assumir o uso se abordados pela polícia}

Assumir o uso, caso abordados por policiais, foi relatado como medida protetora contra a detenção e violência. Es- conder o uso ou "fazer os policiais de bobos" parece não ser boa estratégia, gera mais conflito e repercussões violentas. Falar onde está a droga é visto como uma boa saída, evitando o constrangimento da revista. Segue um exemplo:

"(...) se me perguntam: Você está com alguma droga aí?' Falo: 'Tô sim, tá dentro do maço de cigarro que você tem aí, pode tirar o forro que você vai encontrar'. Eu falo, não tem problema, te juro que não vou ser condenado a 15 anos de cadeia, e nem vou tomar um tiro por causa disso, nem mesmo um tapa nacara." (J47M)

Assumindo o uso, alguns relatos apontam que certos policiais tentam aconselhar os usuários incentivando-os a cessar o uso.

\section{9) Uso de preservativos}

O uso do preservativo foi citado por alguns como estratégia essencial para lidarem com os riscos da prostituição. O uso, no entanto, foi ocasional para a maioria (quando tem o preservativo ou quando o parceiro é desconhecido) e, para alguns, foi considerado desnecessário.

"Usava camisinha, não sempre, mas usava. Não era com todos, porque aqueles que eu já sabia quem eram, que eu conhecia, não usava não." (A21F)

\section{DISCUSSÃO}

Dada a alta taxa de mortalidade entre a população de usuários de $\operatorname{crack}^{8,9}$ e, paradoxalmente, o longo tempo de consumo pela maioria dos usuários que se mantêm vivos ${ }^{10}$, surge a questão: "Como alguns usuários conseguem sobreviver a essa cultura e manter o uso por décadas?"

Alguns fatos têm evidenciado que as mudanças na cultura de crack podem ter contribuído, em alguns casos, para aumentar a expectativa de vida dos consumidores. No início dos anos 1990, estimava-se que um consumidor de crack viveria poucos anos ${ }^{3,21}$. Hoje, é corrente encontrar usuários com mais de cinco anos de consumo ${ }^{4,8}$. Um exemplo dessa afirmação é a amostra deste estudo, que surpreende pelo tempo médio de uso de crack de seus componentes (11,5 anos), mostrando paralelo a estudo americano que também evidenciou a persistência do uso do crack por anos, senão décadas ${ }^{10}$.

Os resultados do presente estudo confirmam a tese de que houve certa "adaptação" do usuário de crack à cultura da droga e a alguns dos riscos gerados por ela. Estes últimos, muito bem percebidos pelos usuários, conforme seus detaIhados relatos.

Aparentemente, algumas estratégias são efetivas em preservar e melhorar a dinâmica de vida dos usuários, principalmente aquelas que permitam ao usuário reconhecer as situações de maior risco - definidas como decorrentes da ilegalidade da droga e dos efeitos psíquicos - e aprender a lidar 
com elas. Pelo fato de essas estratégias terem nascido dentro da própria cultura do crack e, ainda, serem desenvolvidas pelos próprios consumidores, elas parecem ter sido mais facilmente absorvidas. Boyd et al..22, em trabalho realizado no Canadá, concluem que as medidas de redução de danos são mais efetivas quando repassadas por meio das práticas correntes dos usuários e, ainda, pelos seus parceiros.

A morte surgiu como o risco inerente ao consumo de crack mais temido pelos usuários, mas que, quando evitado, permite a manutenção da dependência por muitos anos. Esteve distribuída nas três classes de risco, de forma que a maior parte das estratégias visa driblar a possível morte.

Nesse contexto de risco de morte, Ribeiro et al. ${ }^{8}$ apresentam os homicídios como principal causa de morte entre usuários de crack. Diante disso, no presente estudo as questões relacionadas à ilegalidade da droga, principalmente tráfico e polícia, foram exaltadas. Haasen e Krausz ${ }^{23}$ também afirmam que os homicídios relacionados ao crack estão ligados diretamente aos riscos apresentados pelo mercado ilícito de drogas. As estratégias narradas para facilitar as relações tráfico-usuário, muito pouco elaboradas diante dos riscos a que se destinam, parecem muitas vezes evitar prejuízos importantes. Não desafiar o tráfico, respeitando regras aparentemente simples, como não tentar negociação de preço, pagar as dívidas, não causar problemas próximo à bocada, de forma a não despertar a atenção da polícia, ou, ainda, escoIher adequadamente o ponto de compra ou solicitar a droga por um serviço de entrega, pode evitar a morte do usuário.

Ainda nas questões que permeiam a ilegalidade da droga, a literatura, assim como os presentes dados, mostra que o tratamento dessa população pela polícia não se processa de forma nada cordia ${ }^{24}$. A estratégia relatada pelos usuários como mais útil nesse âmbito é assumir o uso para os policiais caso sejam abordados. Foi evidenciado que, com essa estratégia, há melhor aceitação dos policiais do consumo e redução considerável de episódios de violência. Valer-se da mudança na lei de drogas no país (Lei no 11.343/2006 - a qual despenalizou a conduta criminal dos usuários ao dispensar a necessidade de o consumidor flagrado com droga ir à delegacia $)^{25}$ e colocar-se na categoria de usuário é uma estratégia que beneficia, evitando a possibilidade de ser confundido com traficante.

Mostra-se, assim, devido ao acesso da polícia a essa população, uma via para atuação de programas de intervenções incluindo policiais, que desempenhariam papel educativopreventivo com essa população. Assim como Malchy et al. ${ }^{11}$ sugeriram que as políticas para a "rua" devem se basear em programas realistas destinados ao cuidado dessa população.

Em outro bloco de estratégias, aquelas cujo auxílio aos riscos advém da associação de substâncias psicoativas, percebeu-se que elas se destinam a uma série de riscos elencados como extremamente importantes pela gravidade associada. Essa estratégia quebra totalmente o paradigma passado, em que os usuários enfatizavam que não associavam nenhuma outra substância ao consumo de crack ${ }^{3}$. Esse procedimento visava, segundo os consumidores, a não perder ou não modificar os efeitos do $\mathrm{crack}^{3}$. Nos relatos deste estudo, há referência de associações com outras drogas, principalmente com álcool ou maconha, sendo alegado pelos entrevistados que essas drogas modificam os efeitos do crack. Ou seja, o raciocínio do início de implementação do crack - não associar outras drogas ao consumo dessa droga - alterou radicalmente com o decorrer do tempo.

Nessa direção, Magura e Rosenblum ${ }^{26}$ observaram, entre usuários de cocaína, que 60\% apresentavam uso frequente de álcool para alívio de desconforto relacionado ao cessar do uso e fissura. A literatura sugere que essa associação visa atenuar desconfortos, especialmente nos períodos de abstinên$\mathrm{cia}^{27}$. No presente trabalho, observou-se o uso do álcool para diversas finalidades, principalmente para diminuir os efeitos psíquicos desagradáveis, em vários momentos do consumo do crack, inclusive de forma simultânea. Esse achado destoa em parte do de Gossop et al. ${ }^{28}$, que mostram o uso do álcool principalmente como subsequente ao crack.

O uso do álcool, relatado como efetivo para minimizar os principais eventos psíquicos desagradáveis - fissura e sintomas paranoides -, auxiliaria na minimização dos riscos relacionados aos comportamentos adotados em vigência desses sintomas. Assim, provavelmente, essa associação tem importante papel para a sobrevivência do usuário perante esses riscos, porém são necessários outros estudos que analisem em profundidade essa questão. Isso porque é uma associação que gera preocupação pelos vastos problemas decorrentes, seja a curto ou longo prazo, neste último caso pelo temor de mais uma dependência associada. Além disso, há a formação do metabólito cocaetileno. Esse produto da ingestão combinada, cujo tempo de meia-vida é três vezes maior que o da cocaína, culmina em importante estimulação ao usuário, apresenta propriedades mais cardiotóxicas, como aumento da frequência de batimentos cardíacos e pressão arterial, além do maior risco de overdose $e^{26-29}$.

O consumo da maconha juntamente com o crack como estratégia foi associado a diversas finalidades. A principal delas apresentada foi alívio da fissura. Apesar da existência de relato da maconha como indutora da fissura e desenvolvimento de uso compulsivo de mesclado, existiram vários relatos de sucesso atribuídos a essa associação. Labigalini et al. ${ }^{30}$ relatam experiência bem-sucedida com usuários de crack, na qual estes conseguiam substituir crack por maconha a médio prazo. Essa estratégia foi considerada de redução de danos por esses autores, partindo-se da ideia de que a dependência de maconha, caso se instale, é muito menos danosa que a de crack.

Essa associação parece ser mais comum do que originalmente se pensou e, embora existam alguns relatos negativos a respeito do resultado dessa associação, parece que os 
"benefícios" advindos dela, como diminuir a fissura, são verificados. Essa é uma associação que merece um estudo mais aprofundado em relação aos resultados que ela pode produzir e, ainda, a suas desvantagens a médio e longo prazo.

Outras estratégias, em contrapartida, apresentaram-se nos relatos como totalmente prejudiciais aos usuários, por exemplo, usar a droga em grupo. Mostrou-se uma forma de uso que potencialmente agrava as chances de prejuízos, e os relatos mostram que as confusões nos meios coletivos de uso são vastas, geralmente relacionadas com os delírios persecutórios e fissura, desencadeando episódios de embates físicos entre usuários. Latkin et al. ${ }^{31}$ sugeriram que a rede de uso de drogas influencia nos comportamentos em relação ao consumo e leva os usuários a usarem mais droga, tornando-os mais suscetíveis a overdose e compartilhamento de equipamentos.

Quanto à overdose, poucos trabalhos trazem estimativas da prevalência desse evento por cocaína e seus derivados, tampouco examinam fatores sociais e contextuais associados $^{31}$. Mesquita et al. ${ }^{32}$ mostraram que 20\% dos 396 usuários exclusivamente de cocaína entrevistados já haviam sofrido um ou mais episódios dessa natureza, além de 50\% da amostra saberem de um ou mais casos de morte por overdose. Tais autores acreditam que tal evento seja subnotificado, provavelmente por medo de os usuários de se apresentarem como tal ${ }^{32}$.

Quanto às estratégias para evitar overdose, elas concentrarem-se principalmente no controle da quantidade de crack inalado. A estratégia parece importante, uma vez que o usuário, conhecendo minimamente os sinais físicos do limiar de sobredose, consegue dosar a quantidade do crack utilizado. É claro que é uma estratégia que merece cuidado, uma vez que os constituintes químicos do crack provavelmente variam muito a cada pedra (principalmente adulterantes), interferindo nos efeitos. Brunt et al..$^{33}$ evidenciaram um aumento significativo nos adulterantes da cocaína em pó, sendo relacionado com mais efeitos não convencionais.

Diferentemente da overdose, que pode resultar em morte ao usuário por meios não naturais, o HIV, mais prevalente em usuários de crack quando comparado à população geral ${ }^{5}$, pode resultar em morte natural ao usuário. Pode-se entender essa taxa de contaminação e as estatísticas do HIV como a segunda causa mais prevalente de morte entre usuários de $\mathrm{crack}^{8}$ quando são compilados alguns fatores referentes ao estilo de vida do usuário. Além da vasta literatura a respeito do comportamento sexual de risco adotado pelos usuários de crack, principalmente atividades sexuais para obtenção de dinheiro ou droga ${ }^{5-7,34}$, evidenciou-se no presente trabaIho que a estratégia de uso de preservativos é facultativa. Assim, define-se o uso de preservativos como inconsistente, sendo uma estratégia que ainda protege poucos usuários, não impedindo a contaminação e consequente morte pelas consequências do HIV.
A variação de comportamentos entre os usuários foi extensiva a outras estratégias, assim como na identificação de riscos. Assim, sugere-se que para alguns usuários há um déficit na capacidade de reconhecimento ou julgamento de riscos potenciais. Isso os tornaria rígidos ao aprendizado de modalidades de estratégias para lidar com tais riscos. Esses usuários podem representar aqueles mais expostos a maus prognósticos, como DSTs e morte.

A principal limitação do estudo é a impossibilidade de extrapolar os achados a outras populações pelo fato de a amostra não ser representativa.

\section{CONSIDERAÇÕES FINAIS}

Os resultados do presente estudo mostram que importantes mudanças na cultura do crack, principalmente relacionadas ao aumento da expectativa de vida do usuário, estão intimamente relacionadas com a adaptação do usuário a essa cultura. Identificar os principais riscos e desenvolver estratégias empíricas para a sobrevivência foram observadas principalmente no que tange aos riscos decorrentes dos efeitos psíquicos e da ilegalidade da droga. As estratégias que facilitam a relação do usuário com as questões referentes ao mercado ilícito de venda de drogas tem papel decisivo para minimizar episódios de violência e morte.

Cabe ressaltar, em contrapartida, que algumas estratégias podem ter importante papel a curto prazo, porém ao longo do tempo podem até se somarem outras dependências também destruidoras, como é o caso da associação de álcool.

Valorizar o entendimento da dinâmica de vida do usuário de crack, assim como as questões que os permeiam - tráfico, polícia, prostituição -, tem papel essencial no fomento de políticas públicas para assistência a essa população. Propõese a elaboração de outros estudos que contribuam para o melhor entendimento dessa população, para assim se elaborarem políticas públicas mais adequadas e realistas.

\section{AGRADECIMENTOS}

Agradecemos à Fundação de Amparo à Pesquisa do Estado de São Paulo (Fapesp), ao Conselho Nacional do Desenvolvimento Científico e Tecnológico (CNPq) e à Associação Fundo de Incentivo à Psicofarmacologia (AFIP), pelo apoio financeiro para a realização do projeto.

\section{REFERÊNCIAS}

1. Dackis $C A, O^{\prime} B$ rien CP. Cocaine dependence: a disease of the brain's reward centers. J Subst Abuse Treat. 2001;21:111-7.

2. Carlini EA, Galduroz JCF, Silva AAB, Noto AR, Fonseca AM, Carlini CM, et al. II levantamento domiciliar sobre 0 uso de drogas psicotrópicas no Brasil: estudo envolvendo as 108 maiores cidades do Brasil, 2005. CEBRID/SENAD; 2007.

3. Nappo SA, Galduróz JC, Noto AR. Crack use in São Paulo. Subst Use Misuse. 1996:31(5):565-79. 
4. Oliveira LG, Nappo SA. Caracterização da cultura de crack na cidade de São Paulo: padrão de uso controlado. Rev Saude Publica. 2008;42(4):664-71.

5. Azevedo RCS, Botega NJ, Guimarães LAM. Crack users, sexual behavior and risk of HIV infection. Rev Bras Psiquiatr. 2007;29(1):26-30.

6. Duailibi LB, Ribeiro M, Laranjeira R. Profile of cocaine and crack users in Brazil. Cad Saude Publica. 2008;24(4):545-57.

7. Nappo AS, Sanchez ZVM, Oliveira LG. Crack, AIDS, and women in São Paulo, Brazil. Subst Use Misuse. In press. 2010.

8. Ribeiro M, Dunn J, Sesso R, Dias AC, Laranjeira R. Causes of death among crack cocaine users. Rev Bras Psiquiatr. 2006;28(3):196-202.

9. Dias AC, Ribeiro M, Dunn J, Sesso R, Laranjeira R. Follow-up study of crack cocaine users: situation of the patients after 2, 5 and 12 years. Subst Abus. 2008;29(3):71-9.

10. Falck RF, Wang J, Carlson RG. Crack cocaine trajectories among users in a Midwestern American city. Addiction. 2007;102:1421-31.

11. Malchy L, Bungay V, Johnson J. Documenting practices and perceptions of "safer" crack use: a Canadian pilot study. Int J Drug Policy. 2008;19:339-41.

12. World Health Organization. Qualitative research for health programs. Geneva: Division of Mental Health; 1994.

13. Taylor SJ, Bogdan R. Introduction to qualitative research methods. New York: John Wiley \& Sons Inc:; 1998.

14. Patton MQ. Qualitative research and evaluation methods. 3. ed. Thousand Oaks: Sage Publications; 2002

15. Laranjeira R, Rassi R, Dunn J, Fernandes M, Mitsuhiro S. Crack cocaine - a two-year followup of treated patientes. J Addict Dis. 2001;20:43-8.

16. Creswell JW. Research design: qualitative, quantitative and mixed methods approaches. 3. ed. USA: Sage Publications; 2009

17. Biernacki P, WaldorfD. Snowball sampling: problems and techniques of chain referral sampling. Sociol Methods Res.1981;10(2):141-63.

18. ABEP (Associação Brasileira de Empresas e Pesquisa). Critério de Classificação Econômica Brasil [Internet]. 2008 [citado em 2010 Jan 20]. Disponível em: www.abep.org/codigosguias/Criterio_Brasil_2008.pdf.

19. Bardin L. Análise de conteúdo. 3. ed. Lisboa: Edições 70; 2004.

20. Gibbs GR. Qualitative data analysis: explorations with NVivo. New York: Open University Press; 2007.
21. Nappo SA, Galduróz JC, Noto AR. Uso do "crack" em São Paulo: fenômeno emergente? Rev ABP-APAL. 1994;16:75-83.

22. Boyd S, Johnson JL, Moffat B. Opportunities to learn and barriers to change: crack cocaine use in the Downtown Eastside of Vancouver. Harm Reduct J. 2008;5:34.

23. Haasen C, Krausz M. Myths versus evidence with respect to cocaine and crack: learning from the US experience. Eur Addict Res. 2001;7:159-60.

24. Raupp L, Adorno RCF. Circuitos de uso de crack na região central da cidade de São Paulo. Cien Saude Colet. In press. [citado em 2009 Dez 26]. Disponível em: http://www.abrasco. org.br/cienciaesaudecoletiva/artigos/artigo_int.php?id_artigo=2668.

25. Lei $n^{\circ} 11.343 / 2006$. [citado em 2010 Jan 20]. Disponível em: http://www.planalto.gov.br/ ccivil/_Ato2004-2006/2006/lei/L11343.htm.

26. Magura S, Rosenblum A. Modulating effect of alcohol use on cocaine use. Addict Behav. 2000;25(1):117-22

27. Gossop M, Manning V, Ridge G. Concurrent use of alcohol and cocaine: difference in patterns of use and problems among users of crack cocaine and cocaine powder. Alcohol Alcohol. 2006;41:(2):121-5.

28. Gossop M, Manning V, Ridge G. Concurrent use and order of use of cocaine and alcohol: behavioral differences between users of crack cocaine and cocaine powder. Addiction. 2006;101:1292-8.

29. Pennings EJ, Leccese AP, Wolff FA. Effects of concurrent use of alcohol and cocaine. Addiction. 2002;97(7):773-83.

30. Labigalini $E$, Rodrigues $L R$, Silveira DX. Therapeutic use of cannabis by crack addicts in Brazil. J Psychoactive Drugs. 1999;31(4):451-5.

31. Latkin CA, Hua W, Tobin K. Social network correlates of self-reported non-fatal overdose. Drug Alcohol Depend. 2004;73:61-7.

32. Mesquita F, Kral A, Reingold A, Haddad I, Sanches M, Turienzo D, et al. Overdoses among cocaine drug users in Brazil. Addiction. 2001;96(12):1809-13.

33. Brunt TM, Rigter S, Hoek J, Vogels N, Dijk PV, Niesnk RJM. An analysis of cocaine powder in the Netherlands: content and health hazards due to adulterants. Addiction. 2009;104(5):798-805.

34. Malta M, Monteiro S, Lima RMJ, Bauken S, Marco A, Zuim GC, et al. HIV/AIDS risk among female sex workers who use crack in Southern Brazil. Rev Saude Publica. 2008:42(5):830-7. 